\title{
Effectiveness of Tocilizumab in a COVID-19 Patient with Cytokine Release Syndrome
}

\author{
$\underline{\text { Sadettin Uslu }}$ \\ Department of Rheumatology, Ömer Halisdemir University Bor Physical Medicine and Rehabilitation, Training and Research Hospital, Niğde, Turkey
}

Received: $17 / 05 / 2020$

Accepted: 19/05/2020

Published: 22/05/2020

How to cite this article: Uslu S. Effectiveness of tolicizumab in a COVID-19 patient with cytokine release syndrome. EJCRIM 2020;7: doi:10.12890/2020_001731.

Conflicts of Interests: The Authors declare that there are no competing interests.

This article is licensed under a Commons Attribution Non-Commercial 4.0 License

\section{ABSTRACT}

Cytokine release syndrome (CRS) is a systemic inflammatory response that can be triggered by many factors such as infections. CRS in patients with coronavirus disease 2019 (COVID-19) is life-threatening and can occur very rapidly after COVID-19 diagnosis. Tocilizumab (TCZ), an interleukin-6 (IL-6) inhibitor, may ameliorate the CRS associated with severe COVID-19 and thus improve clinical outcomes. We present a case of life-threatening CRS caused by COVID-19 infection successfully treated with TCZ.

\section{LEARNING POINTS}

- Cytokine release syndrome (CRS) is a systemic inflammatory response that can be triggered by COVID-19.

- $\quad$ CRS can be life-threatening in severe COVID-19.

- Tocilizumab may have a role in treating severe COVID-19 patients with CRS.

\section{KEYWORDS}

Tocilizumab, COVID-19, cytokine release syndrome

\section{INTRODUCTION}

SARS-CoV-2 causes a mild to moderate illness characterized by fever and respiratory symptoms, with or without evidence of pneumonia. However, up to $10 \%$ of patients with COVID-19 may develop severe pneumonia with hypoxia, cytokine release syndrome (CRS) and multiorgan failure ${ }^{[1]}$. Tocilizumab (TCZ) is a humanized monoclonal inhibitor of the proinflammatory cytokine interleukin-6 (IL-6) and is licensed for use in the clinical management of CRS ${ }^{[2]}$. Peer-reviewed data on the clinical use of TCZ in severe COVID-19 are very limited. We describe a case of CRS caused by severe COVID-19 infection with a favourable response to TCZ therapy.

\section{CASE DESCRIPTION}

A 41-year-old woman with a history of hypertension, presented with fever, productive cough and general fatigue. She denied any recent travel but had a history of contact with sick people. In the emergency department she was tachypnoeic (respiratory rate of 22 breaths/min), tachycardiac $(130 \mathrm{bpm})$, febrile $\left(39^{\circ} \mathrm{C}\right)$ and hypoxic (oxygen saturation $\left(\mathrm{SpO}_{2}\right)$ of $88 \%$ on room air). Physical examination of the lungs revealed bilateral crackles and wheeze. The white cell count was normal and the absolute lymphocyte count was low (0.61-103/ $\mu$ ), while the erythrocyte sedimentation rate (77; range, $0-20 \mathrm{~mm} / \mathrm{h}$ ) and C-reactive protein levels (110; range, 0-5 mg/l) were increased. D-dimer was $1657 \mathrm{ng} / \mathrm{ml}$ and procalcitonin was normal. Assays for influenza viruses and a respiratory syncytial virus were all negative. A nasopharyngeal swab was positive for SARS-CoV-2 on RT-PCR assay. Computed tomography (CT) at the time of admission revealed bilateral ground-glass 
opacities and consolidation (Fig. 1). The diagnosis of COVID-19 pneumonia was made and treatment with oseltamivir, hydroxychloroquine and low-molecular-weight heparin was initiated. The patient received supplemental oxygen through a nasal cannula at a rate of $4 \mathrm{I} / \mathrm{min}$. Blood and urine cultures were negative.
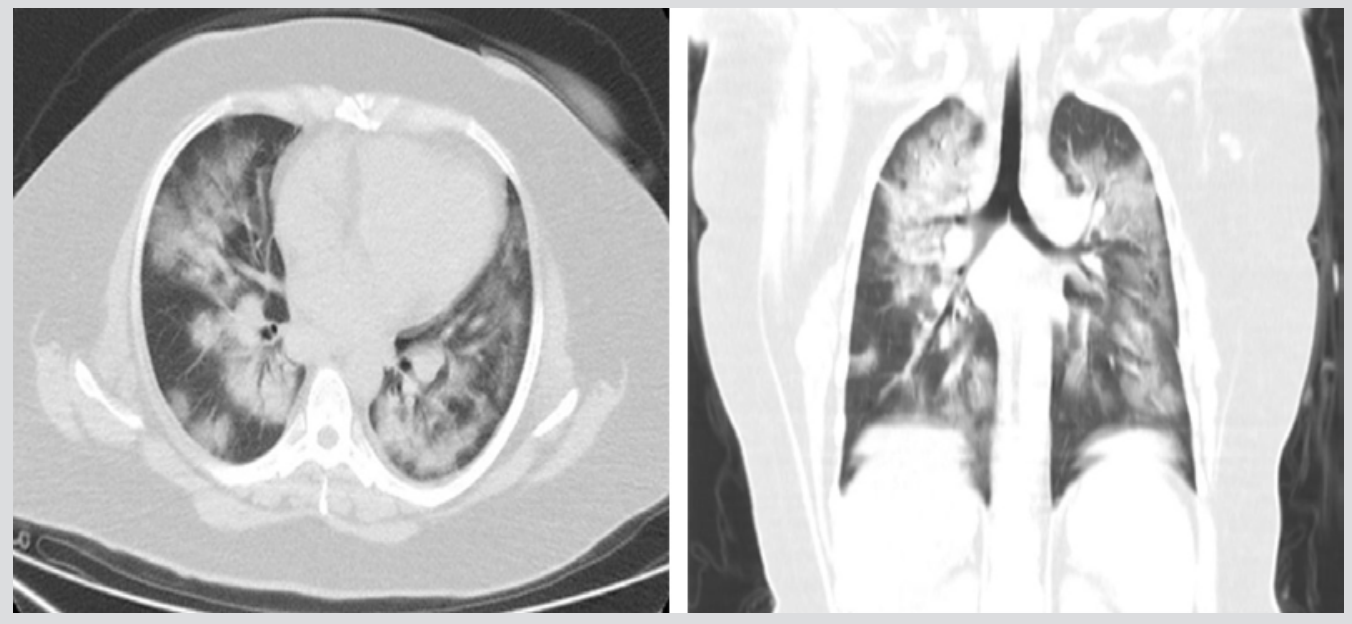

Figure 1. CT scan showing ground-glass opacities and consolidation

After 3 days of hospitalization the patient's clinical condition deteriorated (respiratory rate of 26 breaths $/ \mathrm{min}$ and $\mathrm{SpO}_{2}$ decreased to $78 \%$ ) and she required intensive care unit (ICU) admission. A chest x-ray at the time of ICU admission revealed hazy bilateral lobe opacity (Fig. $2 a$ ). The patient was intubated and diagnosed with CRS. She was given a single intravenous (IV) dose of 400 mg TCZ and IV methylprednisone $60 \mathrm{mg}$ daily for 3 days. Ventilatory support requirements reduced day-by-day. C-reactive protein, ferritin and D-dimer levels dropped from $310 \mathrm{mg} / \mathrm{l}, 3500 \mathrm{ng} / \mathrm{dl}$ and $2123 \mathrm{ng} / \mathrm{ml}$ on the day of ICU admission to $13.2 \mathrm{mg} / \mathrm{l}, 300 \mathrm{ng} / \mathrm{dl}$ and $320 \mathrm{ng} / \mathrm{ml}$ after 3 days, respectively. A chest $\mathrm{x}$-ray showed that the lesions significantly improved within 3 days of TCZ administration (Fig. $2 b$ ). The patient was successfully extubated 5 days after treatment with TCZ. No adverse events were described. On day 10, a clear improvement in the patient's general condition was observed, with an $\mathrm{SpO}_{2}$ of $97 \%$ without any need for supplemental oxygen (Fig. 3).
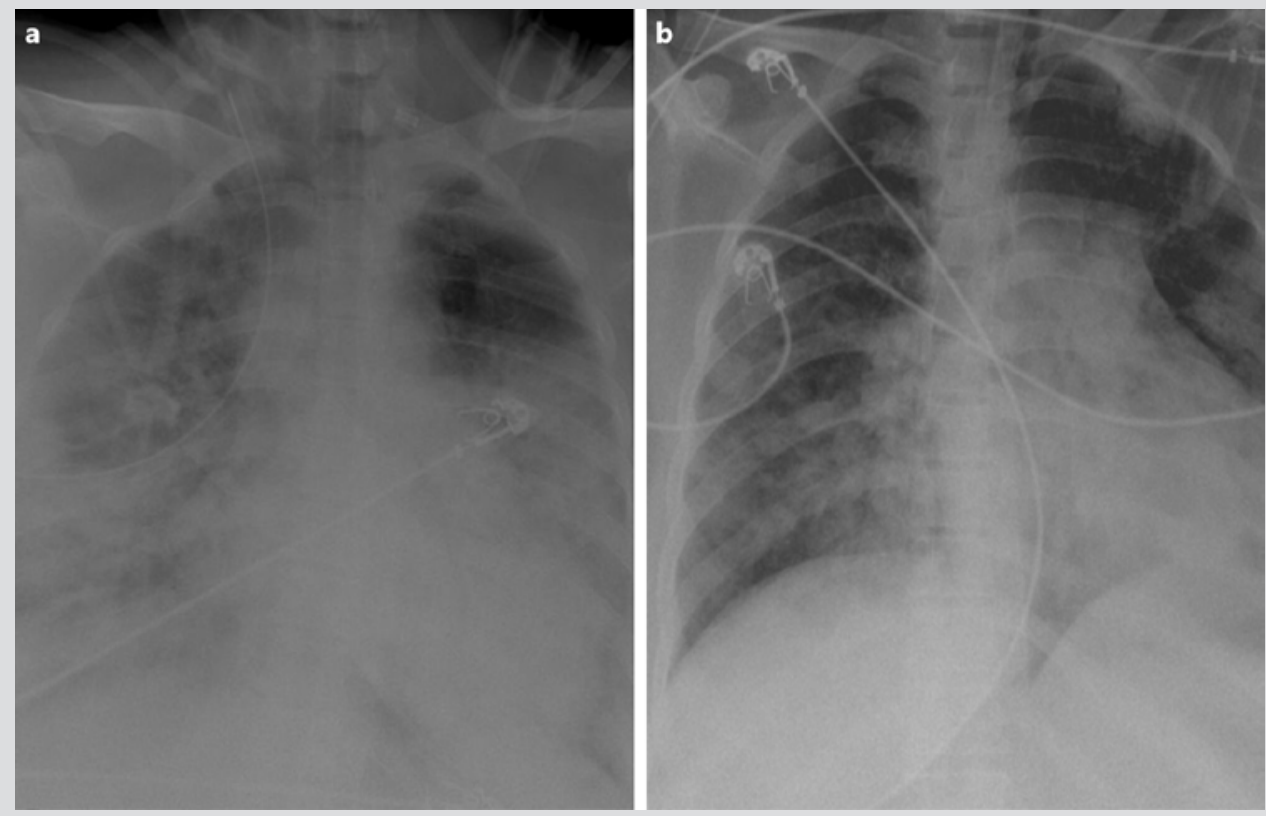

Figure 2. (a) X-ray of the lung, at the time of ICU admission, revealed hazy bilateral lobe opacity. (b) $X$-ray after treatment showed significant improvement 

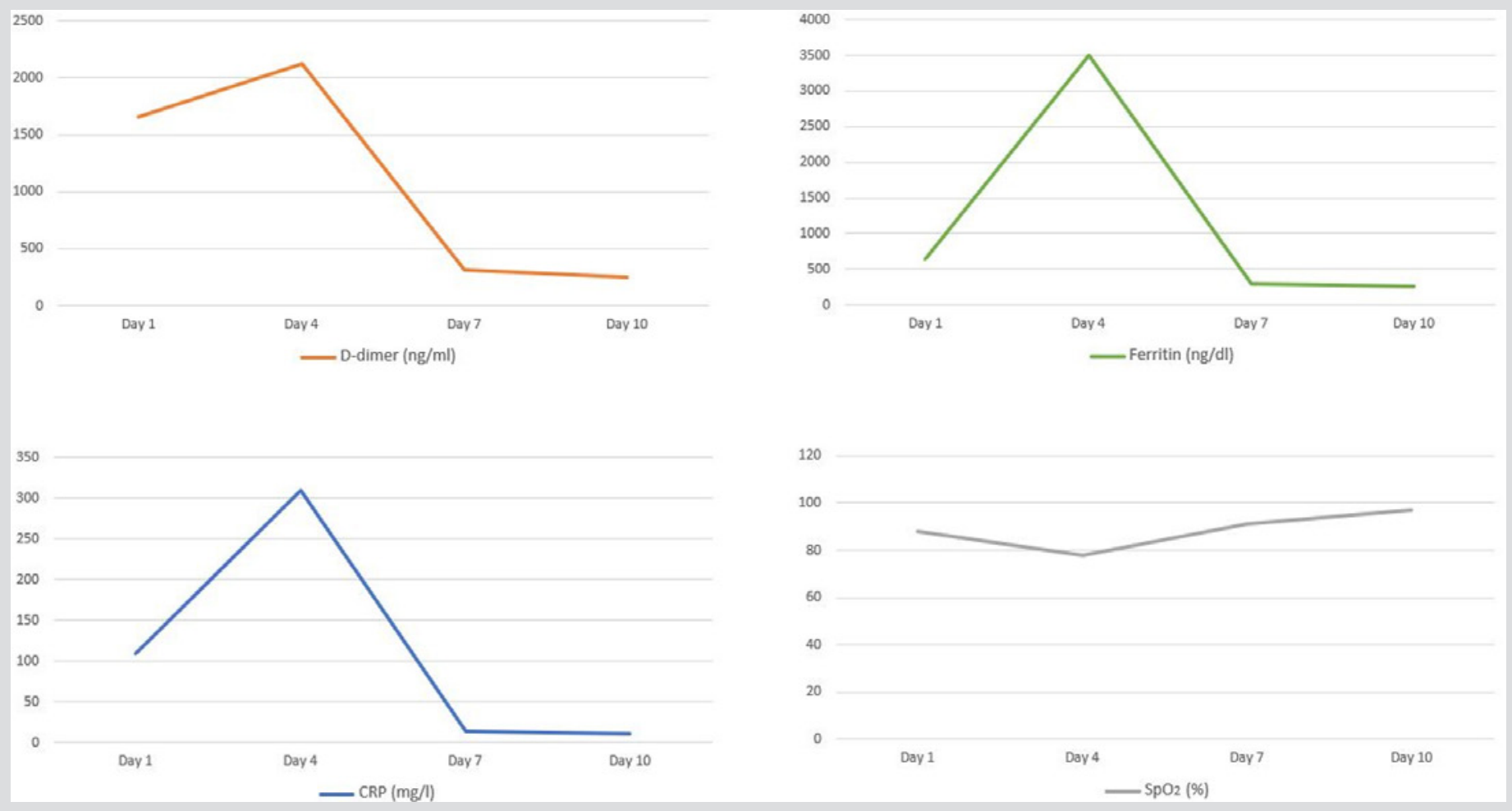

Figure 3. Laboratory and SpO2 data

\section{DISCUSSION}

COVID-19 is associated with increased proinflammatory cytokines. The elevated cytokine levels may also be responsible for the lethal complications of COVID-19. Moreover, histopathological examination of lung tissue from deceased patients with severe COVID-19 showed evidence of extensive alveolar oedema, proteinaceous exudate and patchy inflammatory cellular infiltration. These findings suggest that severe COVID-19 infection is associated with a cytokine storm and pulmonary inflammation secondary to a dysregulated host immune response ${ }^{[3]}$. IL-6 contributes to host defence against infection; however, exaggerated synthesis of IL-6 while fighting environmental stress leads to an acute severe systemic inflammatory response. In the subset of patients with severe COVID-19 infection, this cytokine activation presents with recognized features such as high plasma levels of C-reactive protein, D-dimer and ferritin, and a decreased lymphocyte count. TCZ is a monoclonal antibody against IL-6 and is currently approved to treat chronic inflammatory conditions such as rheumatoid arthritis, giant cell arteritis and polyarticular juvenile idiopathic arthritis ${ }^{[4]}$. CRS in a patient with COVID-19 is life-threatening and can take place very rapidly after COVID-19 diagnosis. Currently, there is no established treatment for COVID-19-associated CRS. TCZ is an option for use in the clinical management of COVID-19 patients with CRS and is associated with a dramatic improvement in inflammatory markers, radiological changes and hypo-oxygenemia.

\section{REFERENCES}

1. Huang C, Wang Y, Li X, Ren L, Zhao J, Hu Y, et al. Clinical features of patients infected with 2019 novel coronavirus in Wuhan, China. Lancet 2020;395(10223):497-506.

2. Le RQ, Li L, Yuan W, Shord SS, Nie L, Habtemariam BA, et al. FDA approval summary: tocilizumab for treatment of chimeric antigen receptor T cell-induced severe or lifethreatening cytokine release syndrome. Oncologist 2018;23(8):943-947.

3. Mehta P, McAuley DF, Brown M, Sanchez E, Tattersall RS, Manson JJ, et al., COVID-19: consider cytokine storm syndromes and immunosuppression. Lancet 2020;395(10229):1033-1034.

4. Liu B, Li M, Zhou Z, Guan X, Xiang Y. Can we use interleukin-6 (IL-6) blockade for coronavirus disease 2019 (COVID-19)-induced cytokine release syndrome (CRS)? J Autoimmun 2020 Apr 10:102452. doi: 10.1016/j.jaut.2020.102452 [Epub ahead of print]. 